\title{
The Nobel Laureate Georg von Békésy's Hearing Theory
}

\author{
Janos Vincze, and Gabriella Vincze-Tiszay
}

Health Human International Environment Foundation, Budapest, Hungary

\begin{abstract}
After Békésy the stapes base moves around two axes: for weaker sounds - rotates around its transverse axis; in case of a strong sound - it moves around its longitudinal axis. Békésy's place theory cannot alone explain the frequency-distinguishing ability of the ear. However, the existence of active amplification further sharpens the frequency-analysing ability of the cochlea. In addition, the different frequency sensitivity of afferent nerve fibres of inner hair cells synergizes with the mechanisms above. Peaked resonance curves are consequences of different threshold sensitivities of nerves connecting to individual hair cells. The frequency, which belongs to the lowest stimulus threshold, is called the characteristic frequency of a nerve. This place assignment of nerve frequencies are formed by the following mechanism in the cochlea. The place of amplitude maxima of progressive waves excited in the basilar membrane shows slight frequency dependence. The mechanism of active amplification forming in outer hair cells amplifies and sharpens the resonances of the basilar membrane. In 1961, nobleman Georg von Békésy received the Nobel Prize in Medicine: "for his discoveries of the physical mechanisms of stimulation within the cochlea".
\end{abstract}

Keywords: hearing theory, Georg von Békésy, Nobel-prize, anatomical structure of the human ear.

\section{INTRODUCTION}

In case of two sounds of different frequencies relative pitch is determined by the proportion of frequencies, which is also called the interval. An interval 2:1, which is well known from music, is called an octave. Above 1000 $\mathrm{Hz}$, consonance for an octave means a frequency-ratio larger than 2. The frequencies of oscillations measured according to that differ from the harmonic octaves; this is the so-called melodic octave. Harmonic octaves (in $\mathrm{Hz}$ ): 8016032064012802560 5120. Melodic octaves (in Hz): 80160320640128035407800 . [1]

The ear transforms soft mechanical vibration of air particles into electrical signals, which reach the appropriate part of the cerebral cortex for processing by means of auditory nerves. The cerebellum interprets these complicated signals by determining pitch, tone, loudness, and placement of the sound source. [2]

The height of a sound is determined by the frequency of an acoustic wave (v), namely the number of oscillations that the sound wave performs in the time unit. The higher the sound frequency, the ,higher" the human ear perceives them. According to the frequency, the sounds classify as follows: infrasounds, $(v<16 \mathrm{~Hz})$, proper sounds $(16$ $\mathrm{Hz}<v<20 \mathrm{kHz})$, ultrasounds $(v>20 \mathrm{kHz})$. The infrasounds and the ultrasounds cannot be perceived by the human ear. [3]
The frequency range of hearing varies greatly from individual to individual; it is rare for a person to be able to hear the full hearing range of 16 to $20,000 \mathrm{~Hz}$. The ear is relatively insensitive to low-frequency sounds; for example, at $100 \mathrm{~Hz}$ its sensitivity is roughly 1,000 times lower than at $1,000 \mathrm{~Hz}$. The sensitivity of high-frequency sounds is greatest in infancy and gradually decreases throughout life, making it difficult for an adult to hear sounds above $12,000 \mathrm{~Hz}$.

\section{THE ANATOMICAL STRUCTURE OF THE EAR}

The hearing analyser consists of two main systems: the peripheral hearing system, formed of the outer ear, the middle ear and the inner ear and the central hearing system, which contains the nervous pathways which ensures the transmission of the nervous influx and the hearing area where the information is analyzed and the hearing sensation is generated. The peripheral hearing system achieves the functions of transmission of the sound vibration, the analysis of the acoustic signal and the transformation of the acoustic signal in nervous inflow and the generation of the nervous response. [4]

The anatomical structure of the ear is shown in Figure 2. [5] In humans, the organ of hearing, a device for absorbing acoustic stimuli, is hidden in the clavicle of the temporal bone. An amplifier is connected to the receptor device. 


\section{AUDITORY OSSICLES}

There are three tiny bones in the tympanic cavity between the eardrum and the oval opening.

a) Malleus 6-8 $\mathrm{mm}$. The head (capitulum), the neck (collum) and projections can be distinguished on it. The strongest of the latter is the handle (manubrium), which has merged with the eardrum, causing stria mallearis on it. [6]

b) Incus $7 \mathrm{~mm}$. A body and two protruding crura can be separated on it. The body forms a joint with the head of the malleus. Its short crus points backwards, its long crus runs parallel to the handle of the malleus, behind this formula. The lower part widens (processus lenticularis) and forms a joint with the head of the stapes.

c) Stapes $3 \times 3 \mathrm{~mm}^{2}$. On the third auditory bone, a head (capitulum), two crura and a base (basis) are distinguished. The head fits into the lenticular process of the incus and the base fits into the oval window.

It plays an acoustic role, transforming external sound vibrations, amplifying them and then transmitting them to the fluid system of the inner ear. It protects the inner ear from excessive sound effects. [7]

The deflections of the eardrum are transferred to the base of the stapes by the lifting action of the auditory bone chain. Due to the fact that the functional surface of the eardrum is $55 \mathrm{~mm}^{2}$ and that of the stapes base is 3.2 $\mathrm{mm}^{2}$, the pressure at the base of the stapes is 18 times higher than that of the eardrum $(55: 3.2=17)$. This ratio corresponds to a $24.5 \mathrm{~dB}$ increase in sound pressure. To this must be added $2.2 \mathrm{~dB}$, since one crus of the auditory bone chain (one arm of the elevator) is one handle of the malleus, the other crus (the other arm of the elevator) is the long crus of the incus, 1.3 times longer than the handle of the malleus. Thus, the voice guidance system of the middle ear: It causes a pressure increase of $24.5+$ $2.2=26.7 \mathrm{~dB}$. From all this we can conclude that the middle ear acts as a mechanical transformer. [8]

The auditory ossicles can be considered as rigid bars and thus the sound waves propagate in a longitudinal form. In this case, the wave equation

$$
\frac{\partial^{2} \Phi}{\partial t^{2}}=c^{2} \cdot \frac{\partial^{2} \Phi}{\partial x^{2}}
$$

The phase velocity $\mathrm{c}$ for longitudinal waves in a solid medium is given by the following formula:

$$
c=\sqrt{\frac{E}{\rho} \cdot \frac{1}{(3-6) \mu}}
$$

where: E - modulus of elasticity, $\rho$ - density, $\mu$ - Poisson's ratio.

After Békésy [9], the stapes base moves around two axes:
- for weaker sounds - rotates around its transverse axis (Fig. 3a.);

- in case of a strong sound - it moves around its longitudinal axis, then the amplitude of vibration is smaller (Fig. 3b).

We have three (3) auditory ossicles because, with their spatial location, the middle ear is able to amplify weak sounds and at the same time is able to attenuate highintensity sounds.

\section{BÉKÉSY'S THEORY}

Békésy prove that wherever the sound stimulus comes from (through the oval window or by bone conducting), it creates a surface wave from the oval window towards the tip of the cochlea. The propagation speed of the surface wave depends on the increasing width and looseness of the membrana basilaris and, as a result, decreases with distance from the oval window $(45 \mathrm{~m} / \mathrm{s}-2 \mathrm{~m} / \mathrm{s})$. [10]

Surface waves caused by high sounds occur in a narrow, tight area near the windows, while fluctuations caused by deep sounds occur at the far, wider, loose ends. At deep sounds, the fluctuation fills the entire length of the membrana basilaris, while at high sounds it fills only the front. The vibrations of the membrana basilaris bend the hair cells of the organ of Corti affected by the traveling waves, creating an electrical potential difference.

Figure 5. shows the cross-section of the cochlea along its entire length with three different chambers: the scala vestibuli, the scala tympani, and the cochlear duct.

The cochlea is filled with fluid and surrounded by a solid, bony wall. It contains two types of fluid: perilymphet (in the scala vestibulit and scala tympanit canals) and endolymph (in the cochlea); the total capacity of the cochlea is only a fraction of a drop. Perilymph is similar to spinal fluid, while endolymph is similar to intracellular fluid. The two fluids are separated by two membranes: the Reissner membrane and the basilar membrane. The Reissner membrane is very thin, approx. two cells thick.

The auditory nerve endings associated with stimulated hair cells sum up these potentials, and transmit a series of action potentials to the brain depending on the intensity of the stimulus. In the process of hearing, inner hair cells fulfill the traditional mechanoelectrical transducer function. As a result of sound stimulation, the hair bundles tilt, generating a change in potential in the membranes of the hair cells. In the event of a depolarizing change, an increase in the frequency of the action potential of the nerve cell attached through the synapse occurs, which indicates the state of stimulation. Since every inner hair cell has an afferent nerve ending, acoustic stimuli with different frequencies are mapped to different parts of the brain's auditory centre due to nerve connections. Thus, the perception of frequency is locally coded. [11] 
In 1961, nobleman Georg von Békésy received the Nobel Prize in Medicine: "for his discoveries of the physical mechanisms of stimulation within the cochlea". The results of this research were carried out in Budapest, and he also published his results before World War II. So it is very important to note that Békésy received the Nobel Prize in Medicine for his research in Hungary. [12]
Georg von Békésy published his new hearing theory based on his epoch-making experiments, the local separation of pitch perception, in the journal Physikalische Zeitschrift between 1928 and 1930. [6, 7, 8, 9].

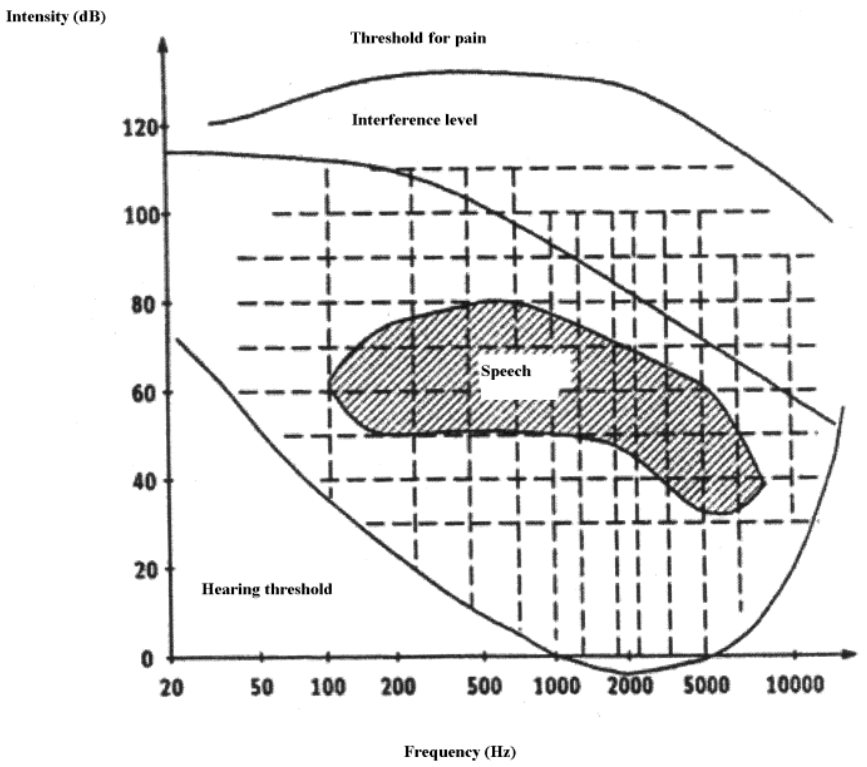

Fig.1. The frequency and intensity sensing range of hearing

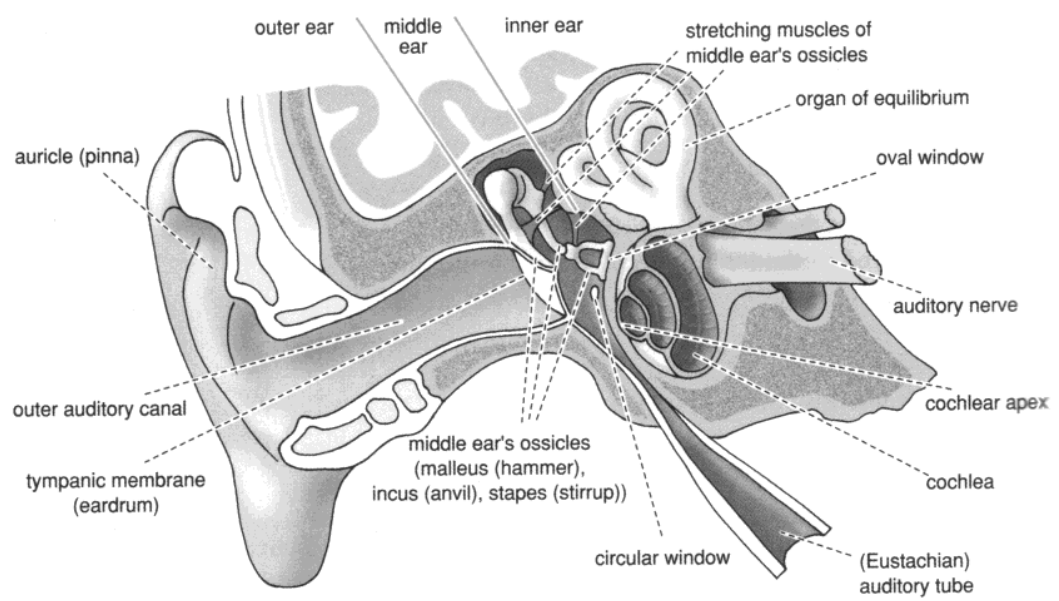

Figure 2. Anatomical structure of the ear 


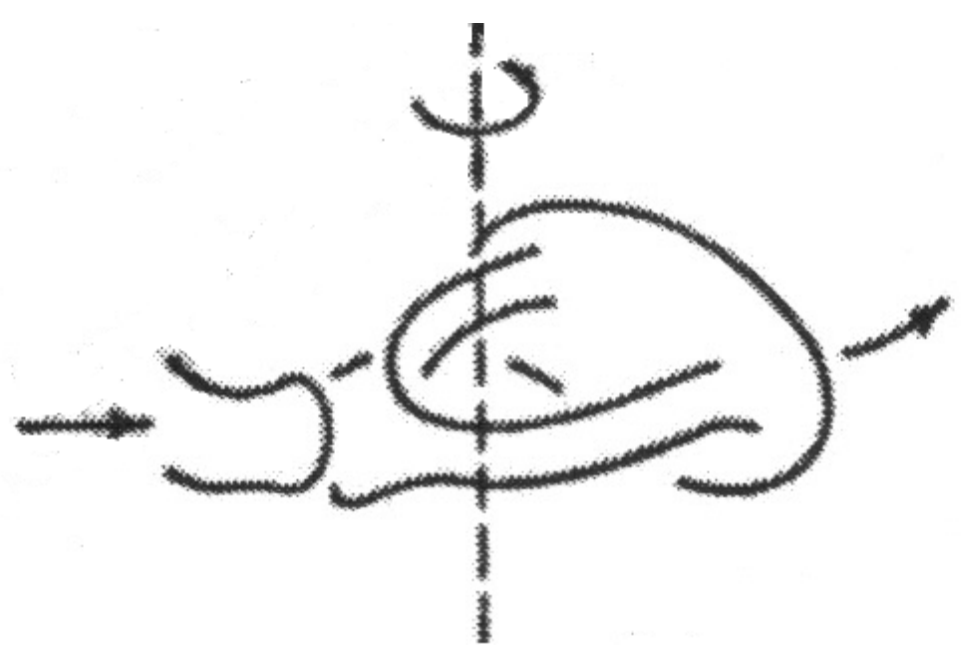

Figure. 3a. In case of a weaker sounds

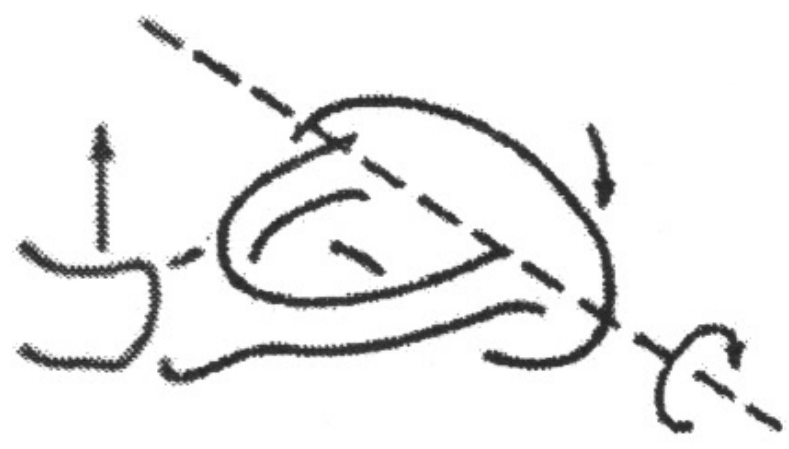

Figure. 3b. In case of a strong sound

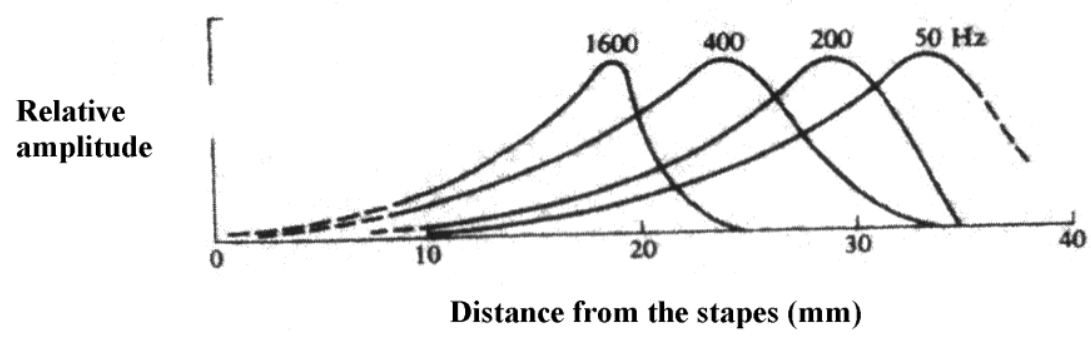

Figure. 4. The relative amplitude of the displacement of the basilar membrane serves as a function of the distance from the stapes for many different frequencies. 


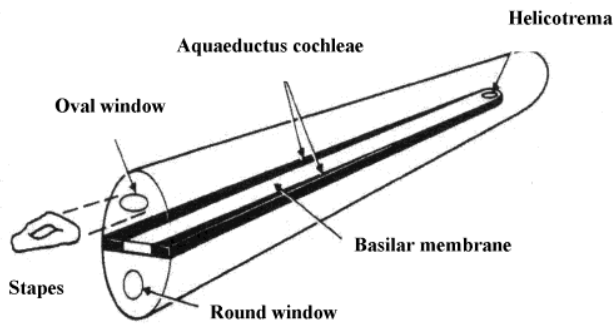

(a)

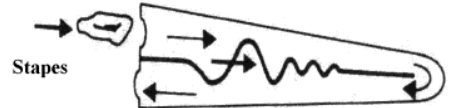

(b)

Figure 5. Schematic diagram of the cochlea (a)

and the part cut from the cochlea (b)

\section{MASKING}

When an ear is exposed to two or more different sounds, one can mask the other in the traditional sense. [13] In the case of a simultaneous sound effect, the simultaneous masking is perhaps best explained by the fact that the hearing range of the weaker sound is raised by the louder sound, and the extent of this also depends on the frequency of the two sounds. [14] Clear sounds, complex sounds, narrow and broadband noises can all mask other sounds in different ways [15].

Some interesting conclusions can be drawn from the relevant masking attempts:

1. Clear sounds that are closely related in frequency overlap more than sounds that are widely spaced in frequency.

2. A clear sound masks higher frequency sounds better than lower frequency sounds.

3. The higher the intensity of a masking sound, the wider the frequency threshold it is able to mask.

4. Narrowing by narrowband noise has the same properties as masking by a clear sound; again high frequency sounds are covered more effectively than those with a lower frequency than the masking noise [16].

\section{REFERENCES}

[1] J. Vincze, Biophysics of the Phonation and of the Hearing, NDP P., Budapest, 2008, pp. 43-76, 121-178.

[2] J. Vincze, Biophysics, 1th Ed. NDP P. Budapest, 1990, pp. 79-102.

[3] J. Vincze, Biophysics, 5th Ed. NDP P. Budapest. 2015, pp. 143-202.

[4] K.. H. Russell K. H., B. J. Roth, Intermediate Physics for Medicine and Biology. Elsevier., 2019, pp. 57-74.

[5] J. Vincze, The Structure and Biomechanics of the Human Skeleton. NDP P., Budapest, 2001, pp. 135-158.

[6] G. von Békésy, „Zür Theorie des Hörens; die Schwingungsform dér Basilarmembran,“ Phys. Z., 1928; 29: pp. 793-781.

[7] G. von Békésy, „Zür Theorie des Hörens; über die Bestimmung des einem reinen Tonempfinden entsprechenden Erregungsgebietes dér Basilarmembran vermittelst Ermüdungs-ercheinungen," Phys. Z., 1929; 30: pp. 115-125.

[8] G. von Békésy, „Zür Theorie des Hörens; über die eben merkbare Amplitu- den- und Frequenzánderung eines Zones: Theorie dér Schwebungen,” Phys. Z., 1929; 30: pp. 721-745.

[9] G. von Békésy, „Zür Theorie des Hörens; über das Richtungshören bei einer Zeitdifferenz oder Lautstárkenungleicheit dér beiderseitigen Schalleinwirkungen," Phys. Z., 1930; 31: 824-35, pp. 85768.

[10] G. von Békésy, Experiments in Hearing, McGraw-Hill Book Company, New York, 1960..

[11] G. von Békésy G, „Some Biophysical Experiments from Fifty Years Ago,” Annu. Rev. Phsyiol. 1974; 36(1): pp. 118.

[12] J. Vincze, Georg von Békésy. NDP K., Budapest, 2019, pp. 55-79.

[13][13] J. Vincze, The Nobel Laurate, biophysicist Georg von Békésy - Path of Life. NDP P. Budapest, 2021, pp. 99-140.

[14] J. Vincze, G. Vincze-Tiszay, "Prof. Dr. nob. georg von Békésy Nobel Laurate," Humanities Social Sciences, 2020; 8(5): pp. 145-150.

[15] J. Vincze, Medical Biophysics, NDP P., Budapest, 2018, pp. 33-56.

[16] J. Vincze, Biophysical Vademecum, NDP P., Budapest., 2021, pp. 71-90. 